\title{
Transformation durch Rezeption?
}

Möglichkeiten und Grenzen des Rechtstransfers am Beispiel der Zivilrechtsreformen im Kaukasus und in Zentralasien

Hrsg. v. Eugenia Kurzynsky-Singer

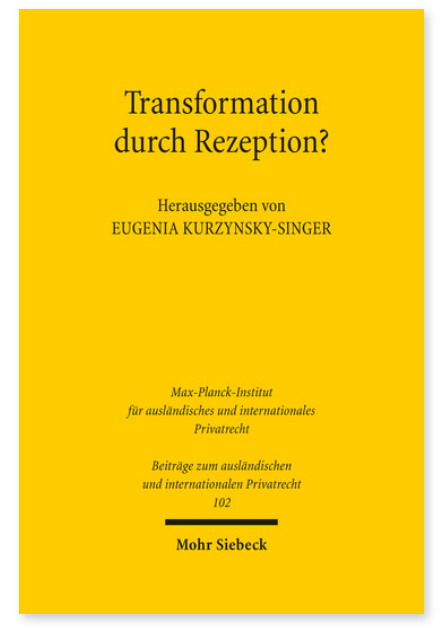

2014. XIV, 512 Seiten. BtrIPR 102

ISBN 978-3-16-153320-4

DOI 10.1628/978-3-16-153320-4

eBook PDF 99,00€

ISBN 978-3-16-153319-8

Leinen $99,00 €$
Die jüngeren Transformationsprozesse in den Rechtsordnungen des postsowjetischen Raums bieten eine gute Gelegenheit, das Phänomen des Rechtstransfers zu untersuchen, weil die durchgeführten Reformen durch eine deutliche Orientierung an westlichen Vorbildern geprägt sind. Im vorliegenden Band wird ein theoretisches Modell zur Erklärung der Wirkungsweise von legal transplants und zur Beurteilung ihrer Erfolgsaussichten aus einer ex ante-Sicht vorgeschlagen. Dieses von Eugenia Kurzynsky-Singer herausgearbeitete Modell stützt sich auf Ergebnisse mehrerer Einzelstudien von Nachwuchswissenschaftlern aus Ländern des Kaukasus und Zentralasiens zu ausgewählten Rechtsfragen ihrer Heimatrechtsordnungen, die hier ebenfalls abgedruckt sind. In zwei weiteren Beiträgen wird das Phänomen der legal transplants in den soziologischen Kontext gestellt sowie die Zivilrechtsentwicklung im Kaukasus und in Zentralasien beschrieben.

Inhaltsübersicht

Inhaltsübersicht:

Teil I : Das Phänomen der legal transplants

Eugenia Kurzynsky-Singer: Wirkungsweise der legal transplants bei den Reformen des Zivilrechts - Natalia Pankevich: Phenomena of Legal Transplants Related to the Social Model of the Post-Soviet Countries - Walter Grenz:

Zivilrechtsentwicklung im Kaukasus und in Zentralasien - Eugenia Kurzynsky-Singer: Das Verbot der Gesetzesumgehung im deutschen Recht als ein potentielles legal transplant

Teil II : Legal transplants als law in action. Untersuchungen zu einzelnen Fragen des Zivil- und Wirtschaftsrechts in den Staaten des Kaukasus und Zentralasiens

Eugenia Kurzynsky-Singer/Tamar Zarandia: Rezeption des deutschen Sachenrechts in Georgien - Giorgi Tsertsvadze: The New Georgian Arbitration Law in Practice - Ketevan Giorgishvili: Das georgische Verbraucherrecht - Giorgi Vashakidze: Kodifikation des Internationalen Privatrechts in Georgien - Irina Pak: The »Point of Confusion« in the Uzbek Trade Marks Act 1994 - Iroda Djuraeva: Personal Non-property Rights of Minors in Uzbekistan - Zhannat Dosmanova: Kontrakt über die Nutznießung von Bodenschätzen nach dem Recht der Republik Kasachstan

Teil III : Materialien der Konferenz »Entwicklung des Privatrechts im Kaukasus und in Zentralasien. Transformation mittels legal transplants?"

Jürgen Basedow: Georgien und die Europäisierung des Privatrechts - Lado Chanturia: Die Entwicklungstendenzen im Zivilrecht der Länder des Kaukasus und Zentralasiens - Elchin Usub: Entwicklung des Zivilrechts Aserbaidschans - Walter Grenz/Alexander Shmagin: Konferenzbericht »Entwicklung des Privatrechts im Kaukasus und in Zentralasien. Transformation mittels legal transplants?« am 18. und 19. Oktober 2012 in Tiflis

Eugenia Kurzynsky-Singer Geboren 1975; 2001 Erstes Juristisches Staatsexamen; 2004 Promotion; 2006 Zweites juristisches Staatsexamen; 2018 Habilitation; 2007-2018 wissenschaftliche Referentin am Max-Planck-Institut für ausländisches und internationales Privatrecht, Hamburg, Leitung des Referats Russland und weitere GUS-Staaten; seit 2019 freiberufliche Expertin für das Recht im postsowjetischen Raum (www.kurzynsky.de).

Jetzt bestellen:

https://mohrsiebeck.com/buch/transformation-durch-rezeption-9783161533204?no_cache=1 order@mohrsiebeck.com

Telefon: $+49(0) 7071-923-17$

Telefax: +49 (0)7071-51104 